\title{
Violencia familiar y Conciliación
}

\section{Iván Ormachea Choque}

«PRIMERO.- Que, don Guillermo T. reconoce que siempre le faltó a su convivienta Caty R. del cual está arrepentido y pide disculpas y manifiesta que de hoy en adelante hará todo lo posible porque su hogar marche muy bien y se compromete a respetar a su convivienta que está gestando de cinco meses y a su menor hija de dos años Fiorela para el cual trabajará mucho y hará lo posible de vivir muy bien.-

SEGUNDO.- Por su parte doña Caty R. manifiesta que es cierto que su conviviente siempre la maltrató pero por sus niños pide que cambie su esposo y le perdona de todo lo que le hizo y hará todo lo posible porque de hoy en adelante su hogar marche muy bien por el bien de sus niños y pide además que nunca su esposo vuelva a maltratarla [...] [sic]»

"Acta de Conciliación de un Centro de Conciliación, 1996".

\section{Introducción*}

Uno de los temas más controvertidos dentro del campo de la conciliación y mediación ${ }^{1}$ se refiere a la pertinencia de estos mecanismos en casos de violencia familiar. ${ }^{2}$ Algunas instituciones se han manifestado

* Mi profundo agradecimiento a la Dra. Carmen G. Arias Otárola por sus valiosos comentarios sobre este artículo.

1 Para los fines de este artículo usaremos los términos mediación y conciliación como sinónimos.

2 Al referirnos a la violencia familiar dentro del contexto de la conciliación, nos referimos fundamentalmente a la violencia contra la mujer por ser el segmento que es más proclive a sufrir los efectos de la violencia familiar. (Así lo asegura el Reporte sobre violencia contra la mujer, sus causas y consecuencias de la Comisión de Derechos Humanos de las Naciones 
en contra de esta posibilidad y otras, en cambio, no han descartado la posibilidad de utilización de este mecanismo en este tipo de situaciones.

Sin embargo, la legislación peruana ha venido gradualmente introduciendo un conjunto de normas en las cuales se faculta a diversas entidades a realizar funciones conciliatorias en casos de violencia familiar. La Ley No 26260 - Ley de Protección frente a la Violencia Familiar- reconoce dos instancias conciliatorias obligatorias dentro de su procedimiento, a cargo inicialmente del Ministerio Público a través de las fiscalías de Familia, y posteriormente del Poder Judicial por la vía de los juzgados especializados en Familia. Del mismo modo, las defensorías del Niño y el Adolescente debidamente autorizadas podrán llevar adelante audiencias de conciliación en situaciones de violencia familiar, según lo prescribe el artículo $48^{\circ}$, inc. c del Código de los Niños y Adolescentes (CNA), en concordancia con el artículo $30^{\circ}$ de la Ley $\mathrm{N}^{\circ}$ 26260. Además, de acuerdo a la Ley No 27007 , de satisfacerse ciertos requisitos, las actas de conciliación de las defensorías adquirirán el valor de título de ejecución en conciliaciones de violencia familiar. En este sentido, la Ley de Conciliación Preprocesal No 26872 ha prescrito como materia conciliable -artículo $9^{\circ}$ - a las situaciones de violencia familiar siendo necesario, por tanto, agotar la instancia conciliatoria antes de iniciar el procedimiento de violencia familiar prescrito por la Ley No 26260. No es sorprendente, entonces, que esta tendencia legislativa sea predominante en el derecho comparado de la región. ${ }^{3}$

La normativa especializada en contra de la violencia familiar empieza, sin embargo, a atraer la atención de instituciones interesadas en los derechos de la mujer, habiéndose realizado a la fecha un importante estudio sobre la aplicación de los mecanismos de protección frente a la violencia familiar, incluyéndose entre ellos a la conciliación. ${ }^{4} \mathrm{El}$ inte-

Unidas del 4 de enero de 1996). Por otro lado, los supuestos y las recomendaciones en torno a la violencia contra la mujer y la conciliación pueden ser fácilmente adecuados a la realidad de otros integrantes de la familia, salvo los niños o adolescentes puesto que la violencia contra los niños no es susceptible de ser conciliada por la falta de capacidad de las víctimas.

3 Según el libro Violencia contra la Mujer: reflexiones desde el Derecho. de Alda Facio Montejo, et. al. Lima, Manuela Ramos, 1996, la legislación de Colombia, Ecuador y Venezuela contemplaban en sus leyes o proyectos de ley contra la violencia familiar una audiencia conciliatoria como parte del procedimiento respectivo.

4 Gina Yañez de la Borda y Jennie Dador. La Violencia Contra la Mujer: aplicación de la Ley de Violencia Familiar desde una perspectiva de género. Lima, Manuela Ramos, 1998. 
rés sobre cuán apropiada es la conciliación en casos de violencia familiar ha propiciado en otros países un debate copioso en torno a la idoneidad de este mecanismo. ${ }^{5}$

Con el ánimo de impulsar la discusión sobre la viabilidad de la conciliación en un contexto de violencia familiar, me propongo en este artículo dar una visión panorámica sobre la realidad de este fenómeno desde la perspectiva de la sicología individual, incidiendo en la relación varón-mujer cuya problemática resulta ser la más frecuente, y los límites y posibilidades que plantea la conciliación en este tipo de casos. Las opiniones -que corresponden únicamente al autor- tratarán de presentar bajo una óptica interdisciplinaria la realidad de la conciliación y de la violencia familiar, para posteriormente argumentar en favor de la necesidad de reestructurar los principios de la conciliación como una posibilidad, muy excepcional y dentro de un conjunto de otros mecanismos, de tratamiento de situaciones de violencia familiar.

Finalmente, pretendo postular un conjunto de modificaciones legislativas y propuestas de política para abordar el fenómeno de la violencia familiar desde una perspectiva interdisciplinaria, dentro de un sistema de atención que tenga por finalidad concluir con el ciclo de violencia en el que se ve prisionera la víctima de violencia familiar y sus hijos, antes que privilegiar exclusivamente al mecanismo de la conciliación que presenta serios riesgos para el manejo de este tipo de violencia.

\section{La conciliación y la violencia familiar como materia conciliable}

A raíz de la promulgación de la Ley de Conciliación No 26872 el 13 noviembre de 1997, la comunidad en general ha empezado a prestar un gran interés en este mecanismo. A través de la gestión del Ministerio de Justicia han venido autorizándose los centros de capacitación para formación de conciliadores y los centros de conciliación, y acreditando conciliadores para que puedan asistir a los ciudadanos en la solución de sus conflictos.

5 Autores norteamericanos y canadienses han escrito numerosos estudios y artículos sobre el tema. Para obtener mayor referencia se puede revisar la bibliografía de est a artículo. 
Este deseo de institucionalizar la conciliación, tal cual lo declara el artículo $1^{\circ}$. de la Ley № 26872, ha incentivado a difundir los beneficios de la conciliación a través de diversas actividades en las que no es poco frecuente escuchar que la conciliación -a diferencia de lo que sucede en el proceso adversarial por excelencia, es decir, el proceso judicial- se caracteriza por ser consensual, voluntaria, informal, rápida, poco onerosa, confidencial, cooperativa, neutral y asistida por un tercero especializado en la solución de conflictos.

Otro de los temas continuamente enfatizados es que este sistema conciliatorio -según lo señala artículo $2^{\circ}$ de la Ley No $^{\circ}$ 26872- tiene como sustento el fomento de una cultura de paz, aunque es obvio que la fundamental razón que motivó al legislador a promulgar la ley fue descongestionar los despachos judiciales, lo cual resulta evidente cuando se institucionaliza la conciliación como requisito de admisibilidad para la interposición de la demanda en un importante número de materias judiciales.

Siguiendo la tendencia manifiesta en la legislación contra la violencia familiar en el Perú y en la región, no resultó difícil incluir en la Ley de Conciliación No 26872 a la violencia familiar como materia conciliable. Sin embargo, resulta imperioso en este momento detenerse y meditar sobre las razones que llevaron al legislador a la inclusión del mecanismo conciliatorio en procedimientos para erradicar la violencia familiar -por ejemplo, fiscalías de familia, juzgados de familia, defensorías del niño y adolescente y centros de conciliación-. A mi entender, la respuesta se puede dar planteando hasta cinco hipótesis. La primera es que el Estado considera que a través de este mecanismo se promoverá un mayor acceso a la justicia de las agraviadas. Una segunda hipótesis se centra en el deseo de descongestionar los despachos judiciales, a través de la creación de instancias que puedan atender estos casos. Una tercera, complementa la anterior al referirse a la mejora del sistema de justicia, que, en tanto descongestionado y con menor carga judicial, puede funcionar más eficientemente; la cuarta, considera que casos como los de violencia familiar son casos de menor importancia -Laura Nader diría casos "chatarra" - que merecen ser tratados

6 Ver el artículo de Laura Nader denominado "Controlling processes in the practice of lawm. Obio State Journal on Dispute Resolution Volume 9, Number 1, 1993, pp. 1-25 
por otras vías como la conciliatoria; y la última, que asume que al igual que en otros asuntos de familia la conciliación es el mecanismo adecuado para resolver los problemas de violencia más eficientemente que el proceso judicial.

\subsection{Las fases y efectos de la violencia familiar}

Según el artículo $2^{\circ}$ de la Ley de Protección frente a la Violencia Familiar (No 26260), se entiende por violencia familiar cualquier acción u omisión que cause daño físico o psicológico, maltrato sin lesión, inclusive la amenaza o coacción graves, que se produzcan entre cónyuges, convivientes, ascendientes, descendientes, parientes colaterales hasta el cuarto grado de consanguinidad y segundo de afinidad o quienes habitan en el mismo hogar, siempre que no medien relaciones contractuales o laborales.

En los hechos esta realidad se puede plasmar a través de la violencia psicológica, ${ }^{7}$ la violencia física ${ }^{8}$ y la violencia sexual. ${ }^{9}$

El fenómeno de la violencia familiar presenta un conjunto de dimensiones especiales que no hacen sino envolver a la víctima en un ciclo destructivo, afectando su autoestima dentro de una atmósfera que se caracteriza por el aumento de sentimientos de ansiedad y aislamiento. En este contexto, la víctima sufre de desorden de estrés posttraumático similar al experimentado por víctimas de guerra, torturas o desastres naturales, ${ }^{10}$ lo cual demuestra que los efectos de la violencia familiar son severos y tienen duración prolongada. ${ }^{11}$

7 La violencia psicológica se puede realizar a través de la coerción, la amenaza, el control económico de la víctima, el control de la socialización de la víctima, el poder del varón para tomar decisiones, la instrumentalización de los nińos, minimizar, negar o culpar a la víctima, aislarla, el abuso emocional o la intimidación contra la víctima. D. J. Sonkin, The Counsellor's Guide to Learnbing to Live Without Violence. Volcano, California, Volcano Press.

$8 \mathrm{La}$ violencia física puede presentarse por la vía de los golpes, jalones, empujones, bofetadas, puntapies, ahorcamiento, mordidas, sentarse o pararse forzadamente, quemaduras, escupitajos, ahogamiento, jalando los cabellos, doblando el brazo, colgando a la víctima por el cuello o extremidades y por el uso de cualquier objeto que provoque una lesión corporal. $O p$. cit. Idem

9 La manifestación de la violencia sexual se puede dar por un coito forzado, inserción de objetos, tortura a los genitales o la utilización de la capacidad sexual de la víctima para fines no aceptables para ella. Op. cit. Idem

10 BC Institute on Family Violence. Family violence in British Columbia: A brief overview. Ver página web: http://www.netizen.org/progressive/bcifv/overview/html

11 Resulta curioso que las víctimas de torturas reciban mayor nivel de protección a nivel 
En una situación de violencia grave prolongada o ciclo de violencia familiar -como lo señala Sun y Woods, ${ }^{12}$ refiriéndose al texto de Lenore Walker, The Battered Woman- la pareja que se encierra en una relación violenta experimenta un ciclo de violencia que se manifiesta en tres fases:

2.1.1 La fase inicial de aumento de tensiones: en la cual se presentan incidentes menores que demuestran que el agresor se encuentra tenso, ansioso, e insatisfecho. Por ejemplo, arranques de furia o lanzamiento de objetos. El agresor, entonces, empieza a asumir que la víctima acepta su comportamiento abusivo legítimamente dirigido a ella. La respuesta de la víctima es amable, tierna y culposa por la tensión que experimenta el agresor. La víctima achaca estos actos a factores externos como el exceso de trabajo, las frustraciones del día y empieza a experimentar los primeros síntomas de ansiedad e inseguridad.

2.1.2 La fase intermedia de incidentes de maltrato agudo: esta fase tiene como resultado un número de actos de violencia dirigidos directamente a la víctima y la conciencia de esta última que no le es posible hacer nada para detenerla.

2.1.3 fase final de arrepentimiento amoroso: generalmente se presenta inmediatamente después del maltrato. El agresor cambia repentinamente y se convierte en una persona amorosa, tierna y arrepentida por sus malas acciones. Si bien el agresor quiere comportarse ejemplarmente, consciente o inconscientemente ha definido claramente las relaciones asimétricas de poder entre él y la agredida.

Por tanto, según Sun y Woods -luego de sistematizar data proveniente de diversos estudios empíricos con víctimas de violencia familiar en los Estados Unidos durante la década de los 80s- tenemos un cuadro en el cual el ciclo del maltrato llega a producir:

internacional, siendo impensable promover una audiencia de conciliación entre el torturador y el torturado. Paradójicamente, nuestra legislación norma la realización de audiencias de conciliación entre el agresor y la víctima en diversas instancias. Supongo que todo esto se hace para "preservar a la familia y al matrimonio como célula básica de la sociedad".

12 Myra Sun y Laurie Woods. A Mediator's Guide to Domestic Abuse. New York, National Center on Women and Family Law, 1989. pp. 25-26. 
- La manifestación repetitiva de la violencia.

- El agravamiento de las lesiones físicas o psicológicas a medida que transcurre el tiempo

- El surgimiento de un proceso adictivo de dependencia entre el agresor y la agredida

- El aislamiento social de la víctima (se aleja del contacto con su familia, vecinos y amigos).

- Continuas amenazas del agresor contra sí mismo, la víctima u otros terceros cercanos a ella

- La reducción de la autoestima de la víctima

- La realización de actos de violencia aún después de haberse separado la pareja.

Igualmente, Charlotte Germane (et. al.), ${ }^{13}$ citando otros estudios, añade que la víctima de violencia experimenta:

- Miedo sobre las consecuencias que puede traer consigo el discrepar con el victimario.

- Alto nivel de depresión, introversión y dificultad para expresarse.

Ante esta realidad, aquellas personas que se oponen a la utilización de la conciliación en casos de violencia familiar argumentan fundamentalmente que la conciliación no debe ser utilizada por las especiales circunstancias que atraviesa la víctima.

\section{Argumentos en contra de la conciliación en casos de violencia familiar}

La discrepancia del uso de la conciliación en situaciones de violencia familiar se basa en la abierta asimetría de poderes entre víctima y agresor, la inadecuada o la falta de capacitación de los conciliadores para entender este tipo de problemática y los criterios de tipo ideológico o

13 Charlotte Germane; Margaret Johnson y Nancy Lemon. «Mandatory Custody Mediation and Joint Custody Orders in California: The Danger for Victims of Domestic Violences en Berkeley Women's Law Journal. Fll 1985. Vol. 1 \# 1. pp. 176 y 186. 
principistas. A continuación discutiremos estos argumentos con mayor detalle.

\subsection{La asimetría radical de poderes}

La razón más frecuentemente esgrimida en contra de la mediación y conciliación en casos de violencia familiar se centra en cuestionar el diferencial de poder entre víctima y victimario. Se critica en principio el hecho de que la conciliación asuma que las partes en conflicto tengan igual poder, iguales recursos para negociar e igual capacidad de negociación. ${ }^{14}$

Se afirma que la mujer afectada por el maltrato físico o psicológico no tiene la misma capacidad de negociar con la que sí cuentan los victimarios. Es más, Hart concluye que toda víctima de violencia familiar sabe que discrepar con su victimario la coloca en una posible situación de violencia, razón por la cual evitará este tipo de situaciones. La víctima puede estar incapacitada de expresarse, por tanto sólo los puntos de vista del esposo serán tomados en cuenta ${ }^{15}$. Reforzando esta idea, el perfil de la víctima y del victimario ha demostrado en los Estados Unidos que la historia de abuso entre la pareja da como resultado una mujer que está convencida de su propia indefensión y desvalidez y un marido que se caracteriza por ser manipulador y dominante. ${ }^{16}$

La posibilidad de una intervención del mediador para simetrizar el conflicto es descartada por Hart, quien concluye que los mediadores creen que pueden nivelar las diferencias de poder pero las mujeres maltratadas llevan con ellas el terror que las hace más proclives a ceder. ${ }^{17}$

Por lo tanto, si se reconoce que la mediación logra los mejores resultados cuando las partes tienen un poder de negociación relativa-

14 Barbara J.Hart, Mediation for Battered Women: same song, second verse - little bit louder, little bit worse. Ponencia presentada en la Conferencia sobre Mujer y Mediación. New York University School of Law. Jan. 21-22, 1984 p. 10.

15 Barbara Hart. Op. cit. p. 10

16 Charlotte Germane, Op. cit. p. 176

17 Douglas D. Knowlton y Tara Lea Muhlhauser. Mediation in the presence of Domestic Violence: is it the light at the end of the tunnel or is a train on the track? p. 263. 
mente igual ${ }^{18}$, resulta evidente pensar que este equilibrio es inexistente en una relación víctima-victimario.

Este desbalance de poder propicia, adicionalmente, que la conciliación sea un factor que incremente los riesgos sobre la víctima con lo cual nuevamente se afecta su seguridad.

La crítica ante el desbalance de poderes ha trascendido -para el discurso feminista- la relación víctima-víctimario y se encuentra más bien en un plano anterior y estructural: la desigualdad de género. Se señala en sí que la desigualdad entre varón y mujer es notoria en el terreno económiço, social y personal lo cual puede reforzarse con el mayor poder que tienen los varones, la diferencia de ingresos percibidos por uno y otro sexo, leyes patriarcales ${ }^{19}$ y la dependencia económica de las mujeres en los varones ${ }^{20}$. Esta situación a la larga implica que la mediación y conciliación no hace más que ritualizar la asimetría de poder entre géneros, favorecer a los varones y mantener el injusto status quo. ${ }^{21}$

Adicionalmente, Yañez y Dador, aunándose a la visión anterior de una perspectiva de género señalan que en el caso de la conciliación en violencia familiar se ofrece un grado mayor de complicación, pues la generalidad de las mujeres han sido socializadas con el altruismo que establece vínculos unilaterales donde unos se benefician a expensas de otros. Por lo tanto, cuando ellas llegan a la conciliación y deben iden-

18 Knowlton y Muhlhauser. Op. cit. p. 255. Ver también sobre la necesidad de equilibrar las relaciones de poder en el texto de Christopher Moore. El Proceso de Mediación. Buenos Aires, Granica, 1995

19 Allan E. Barsky, When Advocates and Mediators negotiate, en: Negotiation Journal, Vol. 9 \# 2, April 1993, p. 115

20 Barbara Hart, Op cit. p. 10.

21 Tal afirmación no deja de ser cierta en el tema de alimentos, por cuanto de un estudio cualitativo realizado en diversas sedes conciliatorias privadas y públicas a nivel nacional, se detectó que el promedio de pago por concepto de alimentos por un hijo ascendía a 153 nuevos soles en el período enero-marzo de 1998, siendo más frecuentes los montos de 100 y 120 nuevos soles. Adicionalmente, en el $80 \%$ de las actas que señalaban montos dinerarios se incluían el pago de diversidad de alimentos, medicinas y vestidos aunque bajo una redacción tan poco clara y precisa que hacía muy fácil invitar al incumplimiento de las obligaciones. Iván Ormachea. Ch. Diagnóstico del Estado de la Cuestión sobre la Conciliación en Instancias Estatales y Privadas. Lima, junio 1998 (inédito). pp. 93 y 94. Siendo evidente que estos montos no pueden cubrir el $50 \%$ por ciento de los gastos de un nińo, la pregunta que surge es quién cubre el déficit. La respuesta es obvia: la madre, con lo cual uno se cuestiona si efectivamente la conciliación se convierte en aquel mecanismo que permite "satisfacer adecuadamente los intereses de las partes" o se configura más bien en este caso como el "mal menor expeditivo". 
tificar sus intereses y poner condiciones aparece el conflicto inconsciente, porque ello atenta contra la imagen altruista que ha sido internalizada junto con el género mujer. ${ }^{22}$

Finalmente, si a la abierta asimetría que existe entre el agresor y la víctima -generalmente varón y mujer cónyuges o convivientes- le añadimos la característica neutral e imparcial del conciliador, se tiene como consecuencia una intervención conciliatoria en la cual aquella parte con menor poder y recursos no podrá protegerse frente al poder y la potencial represalia de su agresor.

\subsection{La inadecuada capacitación de los conciliadores}

La falta de conocimiento de los conciliadores sobre la realidad de la violencia familiar, consecuentemente, tiene por efecto un manejo riesgoso e inapropiado del conflicto a través de su criterios, que frecuentemente se basan en creencias, mitos y estereotipos sobre la violencia, la familia y las relaciones de género.

Esta crítica se extiende a la inadecuada o diversa calidad de capacitación que reciben los conciliadores. Como señala Hart, los mediadores no tienen claridad de criterio para determinar qué es lo que persiguen con la conciliación familiar. Algunos creen que se debe mantener la unidad familiar, preservar el interés superior del niño promoviendo la mejor relación entre los padres o la reconciliación, ${ }^{23}$ disolver el vínculo matrimonial de forma amigable y satisfactoria para todos, etc. ${ }^{24}$

Este argumento nos lleva a meditar sobre los programas de capacitación en conciliación. En la actualidad los cursos de capacitación de los centros de capacitación -que funcionan dentro del marco de la Ley de Conciliación No 26872- no han definido claramente cuál es el modelo conciliatorio que postulan para su capacitación, lo cual es pe-

22 Gina Yañez de la Borda y Jennie Dador Tozzini. La Violencia Contra la Mujer: aplicación de la Ley de Violencia Familiar desde una perspectiva de género. Lima, Manuela Ramos, 1998. p. 61.

23 El artículo $7^{\circ}$ original de la Ley No $^{\circ} 26260$ contra la violencia familiar fomentaba una interpretación a favor justamente de la reconciliación entre víctima y agresor. «Art. 7 o.- El Ministerio Público mediante el Fiscal Provincial Civil de Turno, intervendrá procurando permanentemente la conciliación de las parejas y demás familiares en conflicto (...)».

24 Barbara Hart, Op. cit. p. 10. 
ligroso por cuanto puede permitir una excesiva diversidad de formas de intervención de los conciliadores, desde aquellas permisivas que en el caso de la violencia familiar someterían a la víctima a una situación de indefensión, hasta aquellas coercitivas que desdicen de la posibilidad de encontrar alternativas que sean libremente interiorizadas por las partes asegurando de esta forma su cumplimiento. ${ }^{25}$

Más preocupante resulta ser el hecho de que el reglamento de la Ley de Conciliación sólo exija ocho horas de capacitación adicional a las cuarenta horas básicas para especializarse en conciliación familiar (Art. 36), y comprobar que las actividades de capacitación de conciliadores en los dos primeros años de vigencia de la ley han promovido el surgimiento de un gran número de «especialistas en capacitación», una capacitación legalista y pobre calidad en la enseñanza. ${ }^{26}$

Es más, la inadecuada capacitación y los mitos sobre la familia que nos afectan a todos en general -los varones y mujeres conciliadores no son la excepción ${ }^{27}$ - es otro de los argumentos en contra de la conciliación. A partir de la lectura de actas de conciliación en temas de familia y violencia familiar se identifican los siguientes mitos:

- La célula de la sociedad es la familia. Por lo tanto, la mejor familia es aquella que vive conjuntamente, aun existiendo la violencia. ${ }^{28}$

- El acuerdo ayuda a preservar el interés superior del niño. Es decir, el niño debe vivir en todo momento con sus padres, aun cuando exista violencia. ${ }^{29}$

- La mujer ha provocado -al menos en parte- la agresión del esposo.

25 Sobre la forma preocupante como se viene realizando la capacitación de conciliadores dentro del marco de la Ley de Conciliación No 26872, se puede revisar el artículo «Un Leviatán llamado Conciliación Extrajudicial: a propósito de la implementación del sistema conciliatorio creado por la Ley No 26872" de Iván Ormachea Ch., Lima, IPRECON, 1999.

26 Ver el artículo denominado «Un Leviatán llamado Conciliación Extrajudicial: a propósito de la implementación del sistema conciliatorio creado por la Ley № 26872 " de Iván Ormachea Choque, 1999 (op.cit.) y el artículo «Capacitación de Conciliadores según la Ley de Conciliación 26872: primeras experiencias y desencantos" a publicarse en la Revista Nro. 2 de la Academia de la Magistratura de 1999.

27 Estos mitos están presentes en las actas de conciliación de magistrados de familia. Lo curioso es que en su mayoría los magistrados son de sexo femenino. Ver el texto de Yañez y Dador. op. cit.

28 Este mito está presente en el acta de conciliación citada al inicio del presente artículo.

29 Ibid. 
- El padre (agresor) tiene derecho a vivir con sus hijos y los hijos tienen derecho a vivir con su padre (agresor), aunque exista maltrato a su pareja.

- El alcohol es el causante de la violencia contra la mujer. Por lo tanto, si el agresor promete que nunca va a beber cesará la violencia.

- Con el uso de la terapia psicológica se resolverá el problema de la violencia.

- Si se piden perdón y se arrepienten mutuamente cesará la violencia entre la pareja. ${ }^{30}$

- Si ambos "cumplen con sus roles" o se "portan bien» -el varón a trabajar duro y la mujer a cumplir con sus quehaceres domésticoscesará la violencia. ${ }^{31}$

\subsection{Argumento ideológico o principista}

Finalmente, existe otro argumento de corte ideológico que sustenta la oposición contra la aplicabilidad de la mediación a la violencia familiar. Sun y Woods, citando un documento del Instituto Nacional de Justicia de los Estados Unidos, afirman que la mediación no es el foro apropiado para lidiar con casos de violencia familiar por que al aplicarse como sustituto de un proceso penal, se está asumiendo que la violencia contra la mujer no constituye un comportamiento delictivo que merezca una sanción penal. Por otro lado, el incumplimiento de un acta de conciliación no implica ninguna sanción punitiva. Más allá de que la conciliación no propicia que el victimario asuma responsabilidad por su propio comportamiento, el procedimiento de mediación puede implicar que la víctima comparta la responsabilidad del acto delictivo e incluso exigir que ambos cambien para que el victimario no vuelva a maltratar más a la mujer. ${ }^{32}$

30 Ibid.

31 Todos estos mitos son falsos y propician acuerdos lamentablemente opresores contra la víctima. Ver un listado adicional de mitos en la obra de Yañez y Dador. Op. cit. pp. 27-33 y evidencias de actas de conciliación donde quedan legitimados. Este mito está presente en el acta de conciliación citada al inicio del presente artículo

32 Sun y Woods. Op. cit. p. 37. En el texto de Yańez y Dador se citan acuerdos conciliatorios en los que se imponen responsabilidades a la agredida como la de "llegar a su casa de dos a dos y media de la tarde después de trabajar y a no aceptar compromisos en el trabajo" o a "darse todos sus afectos y someterse a su compañero" o "a no concurrir a lugares públicos 
Probablemente ésta sea una de las argumentaciones más contundentes del discurso contrario a la mediación y conciliación en estos casos. Esta paradoja resulta evidente en la forma cómo se ha normado el fenómeno de violencia familiar como materia conciliable en la Ley de Conciliación No 26872. Por un lado, el tercer párrafo del artículo 9० de la Ley No 26872 dice que no se someten a conciliación extrajudicial las controversias sobre hechos que se refieran a la comisión de delitos o faltas, con excepción de la reparación civil; sin embargo, el párrafo anterior del mismo artículo enumera dentro de las materias conciliables del derecho de familia a la violencia familiar, cuando en sí no sólo se trata de un acto delictivo sino de actos que vulneran derechos fundamentales ${ }^{33}$.

Reconocer que los actos de violencia familiar son una vulneración a derechos fundamentales ha quedado consagrado en nuestro ordenamiento jurídico -a diferencia de otros países- en tanto que el Perú ha ratificado la Convención Belem do Pará o Convención Interamericana para Prevenir, Sancionar y Erradicar la Violencia contra la Mujer de 1994. Resulta entendible, desde este punto de vista, que no sea aceptable negociar o conciliar violaciones de derechos fundamentales que afectan la integridad física y psicológica de la persona.

\footnotetext{
y sociales, cuando su esposo no esté presente" pp. 23, 89 y 230-231 respectivamente. Estos acuerdos implican la renuncia de derechos (taxativamente sancionados con la nulidad según el art. 13 de la Ley 26260) y la vulneración a derechos fundamentales.

33 Lourdes Flores. «Protección jurídica frente a la Violencia Familiar». En Alda Facio Montejo, et. al. Violencia contra la Mujer: reflexiones desde el Derecho. Lima, Manuela Ramos, 1996. p. 38. Según Violeta Bermúdez, citando a Nieves Rico, se afecta al derecho a la identidad, puesto que refuerza y reproduce la subordinación de la mujer al varón, así como la distorsión del ser humano; del derecho al afecto, debido a que la violencia es la antítesis de toda manifestación de esa índole; del derecho a la paz y a las relaciones personales enriquecedoras, ya que es una forma negativa de resolución de conflictos; del derecho a la protección, debido a que crea una situación de desamparo, que no proviene del esposo y la familia sino también del Estado, que niega protección a las mujeres, y de la sociedad que invisibiliza el problema; del derecho al desarrollo personal, puesto que las víctimas sufren una parálisis psicológica que les impide desarrollar su potencial creativo; del derecho a la participación social y política, debido a que coarta la realización de actividades extradomésticas (con excepción de la mínimas relacionadas con los roles tradicionales), como la participación en organizaciones, grupos o reuniones; del derecho a la libertad de expresión, y del derecho a una salud física y mental óptima. "La Violencia familiar y su tratamiento en el derecho peruano». Revista de la Academia de la Magistratura. Enero de 1998, Nro. 1, Lima: 1998 p. 223.
} 


\subsection{Otros argumentos}

Entre los argumentos más frecuentemente esgrimidos contra el uso de la mediación y conciliación en casos de violencia familiar se señala:

- No se puede conciliar (arreglar, negociar, etc.) la violencia. Por tanto, se piensa que la violencia no es una materia conciliable

- En la mediación, el mediador no puede brindar las garantías suficientes para evitar la continuación de la violencia. Menos aún exigir al victimario que deje el hogar conyugal o convivencial a partir de su gestión conciliatoria, con lo cual se estaría exponiendo a la víctima a una situación riesgosa para su integridad.

- Existe mucho incumplimiento de las actas de conciliación y no existen mecanismos para exigir su cumplimiento.

- Los mediadores podrían estar sugiriendo que cuando la víctima recibe la intervención apropiada para garantizar la seguridad de la víctima, se ha restaurado el balance de poderes. Esta es una noción errada por cuanto no reconoce el impacto a largo plazo del poder y control que experimenta la víctima. La seguridad física no borra los efectos del terrorismo psicológico.

- Finalmente Yañez y Dador nos brindan un conjunto de razones por las cuales no es viable la utilización de la mediación en la violencia familiar:

1. La mujer maltratada no está a salvo en la mediación

2. La mediación privatiza un proceso legal. Este aislamiento es una forma de ejercer control, beneficiando al agresor.

3. Los mediadores median aun cuando el poder de negociación no es igual, por que creen que ellos pueden resolver cualquier disputa.

4. Los mediadores desdeñan el pasado violento del agresor debido a que se centran en el futuro.

5. La mediación promueve un acuerdo -no la igualdad- ya que el objetivo de la mediación no es necesariamente alcanzar la justicia o equidad sino el acuerdo cuyo contenido podría estar por debajo de los derechos de la víctima.

6. La mediación a menudo se siente como consejería matrimonial. 
7. La mayoría de mediadores comparten los prejuicios de la comunidad. No entienden que las mujeres deben enfrentar problemas de discriminación. ${ }^{34}$

Finalmente, algunas defensoras de los derechos de la mujer rechazan categóricamente la posibilidad de trabajar conjuntamente con los mediadores en la búsqueda de políticas que mejoren la intervención en casos de violencia, por que la mediación -desde su punto de vista- es totalmente contraproducente para la mujer. ${ }^{35}$

\section{Argumentos en favor de la utilización de la conciliación en casos de violencia familiar}

Los argumentos señalados por aquellos que se oponen a la utilización de la conciliación/mediación en casos de violencia familiar, han sido refutados por aquellos que piensan que la conciliación es una posibilidad más de intervención para poner fin a situaciones de violencia familiar.

En principio, se refuta el argumento en contra de la mala capacitación de los mediadores o la falta de ésta. En sí, se señala que muchos de los estudios que demuestran los efectos nocivos de la mediación en casos de violencia familiar se centran en la realización de audiencias de mediación conducidas pobremente por personas no capacitadas o mal capacitadas. ${ }^{36}$ Estos efectos no se producirían ante una mediador/conciliador adecuadamente capacitado en el fenómeno de la violencia familiar y conocedor de las técnicas adecuadas para evaluar el caso previamente, maximizar las condiciones de seguridad de la víctima, evitar la ansiedad que produce el encuentro con el agresor y velar por que la negociación se realice fomentando el balance de poderes entre las partes.

34 Yañez y Dador. Op. cit. pp. 66-69.

35 Barsky. Op. cit. p. 119.

36 Esta situación se presenta justamente en el caso de jueces y fiscales de familia, por cuanto el legislador al haberles encomendado la misión de conciliar conflictos por violencia familiar ha asumido que por gozar de la magistratura cuentan con la capacitación adecuada para manejar estos casos. Creo que si para ser conciliador se requiere agotar un conjunto de requisitos y tener ciertos atributos personales, no todo conciliador puede ser un buen conciliador en asuntos de familia y menos aun en situaciones de violencia familiar. 
Por otro lado, se critica que la mayoría de estudios sobre violencia familiar asuman un paradigma único en el estudio de este fenómeno: la violencia repetitiva y grave del agresor (conviviente o esposo) contra su pareja (víctima) por un período de tiempo prolongado que ocurre sin causar la disolución permanente de la relación. ${ }^{37}$ Razón por la cual se sugiere un mayor estudio de aquellos casos donde la violencia es leve o no prolongada y donde, consecuentemente, aquellas víctimas de situaciones de violencia menor no se encuentran en la situación de aquellas víctimas de violencia prolongada o grave que se utilizan para describir la situación de violencia familiar. Eventualmente, en alguno de estos casos leves podría permitirse la utilización de la conciliación o mediación.

Adicionalmente, se sostiene que la utilización de la mediación en casos donde existe violencia familiar tiene como argumento central el no quitarle a la agredida la posibilidad de beneficiarse de este mecanismo, siempre y cuando los mediadores satisfagan rigurosamente las condiciones necesarias para manejar el caso como, por ejemplo, implementar medidas de seguridad a favor de la víctima. Complementando esta idea, algunos mediadores cuestionan la forma como funciona la vía judicial al tramitar estos casos, por cuanto tiene efectos nefastos para la víctima al hacerla sentir humillada, desacreditada, controlada y avergonzada ya que los abogados de las partes harán todos los esfuerzos para ganar el proceso afectando aún más la relación entre las partes mismas y entre ellas y sus hijos. ${ }^{38}$

Ante esta discusión entre aquellos que consideran a la conciliación como una vía adecuada y aquellos que la consideran nociva para la víctima, resulta necesario definir si la conciliación es o no apropiada para este tipo de problemática.

37 Charles A. Bethel y Linda R. Singer. «Mediation: A new remedy for cases of domestic violences. En: Vermont Law Review. Vol. 7, \# 1 Spring 1982, p. 21.

38 Douglas D. Knowlton y Tara Lea Muhlhauser. "Mediation in the presence of Domestic Violence: is it the light at the end of the tunnel or is a train on the track?.. En North Dakota Law Review. Vol. 70, \# 2, 1994. p. 266. 


\section{La conciliación en situaciones de violencia familiar: ¿un medio apropiado para la solución de estos conflictos?}

En principio, los argumentos en contra de la mediación y conciliación en casos de violencia familiar inciden en tres niveles. Una de las partes ha sufrido un perjuicio directo en su persona -física, sexual o psicológicamente- $y$ por lo tanto se encuentra disminuida y carente de poder con relación al agresor. Este argumento es reforzado a partir de una visión feminista que señala una abierta crítica a la presunción de que el varón y la mujer pueden negociar sus conflictos en igualdad de condiciones.

Un segundo argumento incide en la calidad del tercero conciliador o mediador que interviene en el manejo del caso, y en la capacidad y facultades que posee para administrar y resolver el problema.

Finalmente, existe un argumento de corte ideológico o principista que descarta la utilización del mecanismo privado y confidencial de la mediación por cuanto el Estado se debería manifestar punitivamente contra este tipo de comportamientos delictivos, lo cual queda reforzado en nuestra legislación al haberse ratificado la Convención Belem do Pará en la que se reprime y sanciona la violencia contra la mujer por considerarse una vulneración a un derecho fundamental.

Frente a estos argumentos y a la preocupación manifiesta de las organizaciones de defensa de los derechos de la mujer en los Estados Unidos y en Canadá, se inició un proceso de discusión en 1991 en el que aquellas organizaciones de defensa de la mujer -muy críticas sobre el uso de la mediación en casos de violencia- se reunieron con un grupo de mediadores prestigiosos y pudieron, dentro de un proceso de creación de confianza y solución de problemas elaborar un conjunto de pautas que satisfacieran las preocupaciones de las defensoras de la mujer.

Estas pautas han sido registradas en el documento denominado Report from the Toronto Forum on Woman Abuse and Mediation [Reporte del Forum de Toronto sobre Violencia contra la Mujer y Mediación] que posteriormente ha inspirado la dación de diversas pautas para la Asociación Ontariana de Mediadores de Familia de Canadá (OAFM) y la Academia de Mediadores de Familia de Estados Unidos (AFM). 


\subsection{Pautas para la mediación en situaciones de violencia contra la mujer}

El punto de partida que debe manejar tanto la conciliación como la mediación en casos de violencia contra la mujer se resume en la siguiente premisa refutable:

Si se tiene en cuenta la naturaleza de la conciliación y la finalidad primordial de salvaguardar el interés vital de la víctima, se debe reconocer que la conciliación/mediación puede poner en riesgo su seguridad y bienestar, así como las de terceros ligados a ella.

Por lo tanto, se acepta que la conciliación es un medio riesgoso de intervención en casos de violencia contra la mujer, porque podría afectarse la seguridad e integridad de la víctima y terceros ligados a ellos (hijos, parientes cercanos, etc.). Sin embargo, contrario sensu, se puede interpretar que si estos riesgos no existen la conciliación o mediación podría proceder.

Aún así, el mismo reporte plantea con gran profundidad tres pautas para determinar si es apropiado utilizar la mediación a los casos de violencia contra la mujer ${ }^{39}$ :

1. Entrevistar previamente a las partes por separado.

2. Respetar ciertas condiciones esenciales antes, durante y después de la conciliación.

3. Contar con diversas alternativas a la conciliación para el abordaje global del caso particular.

\subsubsection{La entrevista inicial}

El conciliador en casos de violencia familiar debe inicialmente reunirse con la víctima por separado para:

a) Informarse sobre la gravedad - peligrosidad- del caso y los efectos de la violencia en la víctima y otros terceros.

39 Esta descripción sumamente resumida del documento del Forum de Toronto ha sido tomado del Manual de Conciliación de Iván Ormachea Choque. Lima, USAID-IPRECON, 1999 pp. 104-106 
b) Darle información sobre los alcances de sus derechos y otras alternativas a la conciliación (denuncia ante la fiscalía, iniciación de un proceso judicial, acceso a casas de refugio, asistencia psicológica, etc.).

c) Conocer qué es lo que la víctima desea hacer efectivamente con su situación.

d) Determinar si existen terceros que podrían estar siendo afectados por la violencia existente (hijos, ancianos, etc.).

e) Determinar si la conciliación es el medio adecuado para ayudar a la víctima.

Del mismo modo el conciliador debe reunirse por separado con el victimario para conocer los detalles de la situación y determinar si cuenta con las capacidades necesarias para participar en una eventual audiencia de conciliación.

Con esta información, el conciliador deberá decidir si el caso es susceptible de ser tramitado en la vía conciliatoria, siempre y cuando se cuente con la aprobación de la víctima y la contraparte. El conciliador también tendrá la posibilidad de vetar la decisión de las partes a favor de iniciar una conciliación, si se concluye que el caso resulta inapropiado para la conciliación o no se pueden asegurar las cuatro condiciones detalladas líneas abajo.

5.1.2 Condiciones esenciales antes, durante y después de la audiencia de conciliación

En todo momento se debe asegurar la existencia de las siguientes cuatro condiciones - algunas de ellas han sido reconocidos en el artículo $13^{\circ}$ de la Ley No 26260 y en los artículos $10^{\circ}$ y $23^{\circ}$ del Reglamento de la Ley de Conciliación, D. Sup. No 001-98-JUS:

\section{a. Seguridad}

Antes, durante y después de la audiencia de conciliación, el conciliador -con el soporte del centro de conciliación- debe minimizar los riesgos y la seguridad de la víctima.

Una de las obligaciones esenciales del conciliador es proteger a la víctima y asegurarse que, una vez conocido el caso, se le brinde las máximas seguridades para que no se vuelva a producir violencia. Si bien la Ley No 26260 ofrece algunas posibilidades para lograr este fin 
a través del dictado de medidas de protección y medidas cautelares (Art. $10^{\circ}$ y Art. $11^{\circ}$ ), el conciliador debe visualizar las posibles situaciones de riesgo que va a tener que enfrentar la agredida con el fin de buscar una respuesta adecuada al problema. Por ejemplo, buscar un lugar o casa de refugio, crear un plan de salida de emergencia del hogar si estalla nuevamente la violencia, -citar al agresor en el día de la audiencia- 15 minutos antes de la agredida y dejar salir de la sala de audiencias primero a la agredida y después de un tiempo prudencial al agresor. En otros casos la audiencia de conciliación sólo se realizará por separado antes que en forma conjunta por una cuestión de seguridad.

\section{b. Voluntariedad}

La participación de las partes en la audiencia de conciliación debe ser voluntaria y basada en el consentimiento informado. No se puede, por lo tanto, obligar a una persona a que vaya a una audiencia de conciliación ni exigir la conciliación como requisito dentro o previo a un procedimiento.

\section{c. Capacidad de tomar decisiones}

El conciliador y el centro de conciliación deben velar por que la víctima y el agresor se encuentren con todas sus facultades al momento de tomar decisiones sobre sus derechos e intereses. Si la víctima experimenta miedo, inseguridad o coacción de cualquier clase se debe suspender o poner fin a la audiencia de conciliación. No tiene sentido promover una negociación - asistida por un conciliador-cuando una de las partes no tienen la capacidad de hacerlo.

\section{d. Equidad}

El conciliador debe preocuparse por el logro de acuerdos que sean justos y equitativos, y que no ritualicen la relación asimétrica de poder y control entre las partes. El conciliador, adicionalmente, intervendrá entonces para equilibrar la balanza de poder entre las partes, basándose en el principio de empoderamiento. 


\subsubsection{La audiencia de conciliación}

De realizarse la audiencia, se deben tomar en cuenta estas cuatro condiciones y se observará la dinámica de relación entre las partes, para evitar que la audiencia de conciliación y el eventual acuerdo resulten en una pseudo solución a la problemática de la violencia.

Durante las discusiones las partes podrán llegar a definir su situación conyugal y familiar, llegando a acuerdos sobre:

- Alimentos.

- Tenencia y visitas de los hijos.

- Situación de los bienes.

- Separación o divorcio de la pareja.

- Reparación de daños materiales.

- Indemnización a la víctima.

Podríamos entonces concluir que la utilización de la conciliación o mediación para el manejo de situaciones de violencia familiar se torna riesgosa 3/4 por cuanto de llevarse inadecuadamente puede generar serios perjuicios a la víctima $3 / 4$, y necesariamente excepcional $3 / 4$ en tanto no todos los casos pueden ser susceptibles de canalizarse por la vía conciliatoria $3 / 4$ tal cual lo señala el documento del Forum de Toronto. Ante este panorama, resulta imprescindible redefinir los principios que gobiernan la conciliación en favor del logro del objetivo de lograr el cese definitivo de la violencia familiar.

\section{Redefinición de los principios de la conciliación}

Debido a las especiales características de la problemática en torno a la violencia contra la mujer o familiar, los principios de la conciliación sufren un conjunto de cambios para adecuarse a la realidad del tipo de conflicto que tratará. A continuación detallamos los más importantes principios y sus respectivos cambios.

6.1 El principio de voluntariedad debe de respetarse necesariamente desde el momento de la convocatoria. Si bien los sistemas conciliatorios, en general, admiten cierto grado de obligatoriedad como, por 
ejemplo, obligar a que las partes intenten un acuerdo conciliatorio, ${ }^{40}$ obligarlos a que asistan a la audiencia de conciliación so pena de mul$\mathrm{ta}^{41}$, etc., los sistemas conciliatorios obligatorios resultan siendo injustos y riesgosos para la víctima de violencia en tanto las obligan a enfrentar nuevamente cara a cara, a sus victimarios afectando su integridad física y psicológica. La decisión sobre la realización de la audiencia de conciliación debe recaer fundamentalmente en la agredida, aunque el conciliador tiene el poder de veto si considera que no existen las circunstancias necesarias para llevar a cabo la conciliación o si habiendo existido éstas, se han deteriorado. Lamentablemente, ni la Ley No 26260 contra la violencia familiar ni la Ley de Conciliación No 26872 han tomado en cuenta este principio. Por otro lado, el principio de voluntariedad también se exterioriza al momento de la audiencia conciliatoria, en el sentido de que no se ejercerá o se permitirá el ejercicio de la coerción contra la víctima para obtener la suscripción de un acuerdo. Esta pauta ha sido reconocida en el Art. $23^{\circ}$, numeral 5 del reglamento de la Ley de Conciliación.

6.2 El principio de confidencialidad debe de respetarse aunque velando en todo momento que la confidencialidad no ampare posibles situaciones pasadas, presentes o futuras de violencia contra los integrantes de la familia y la víctima. El conciliador debe estar muy consciente de la información que se intercambie durante el procedimiento de conciliación, y romperá con la obligación de mantener la reserva cuando detecte alguna información que pueda afectar o haya afectado a la integridad física o psicológica de los integrantes de la familia. En este último supuesto comunicará los sucesos a las autoridades pertinentes. La Ley de Conciliación No 26872 reconoce la excepción a la confidencialidad, aunque de forma imperfecta. ${ }^{42}$

40 Este es el sistema que prevé la Ley de Conciliación peruana No 26872 en su artículo $6^{\circ}$.

41 La Ley de Mediación y Conciliación argentina No 24573 sanciona la inasistencia con una multa equivalente a 30 dólares americanos; eso sí, la violencia familiar no es materia conciliable.

42 Artículo $8^{\circ}$ de la Ley de Conciliación y Art. $8^{\circ}$ de su reglamento. Ver los comentarios en el texto Análisis de la Ley de Conciliación Extrajudicial de I. Ormachea pp. 31-33 y 5053. 
Cabe señalar, sin embargo, que resulta paradójico exigir el respeto al principio de confidencialidad cuando en situaciones de violencia familiar es frecuente encontrar acciones de tipo delictivo como parte del ciclo de violencia. En este supuesto, el conciliador debe evaluar -tanto durante la entrevista inicial como durante todo el procedimiento conciliatorio- si el caso resulta siendo pertinente para la vía conciliatoria.

6.3 Los principios de imparcialidad y neutralidad son redefinidos basándose en la finalidad que persigue la conciliación en este tipo de casos. El conciliador deberá mantener su rol imparcial o neutral durante la conducción del procedimiento, pero no puede ser ni imparcial ni neutral frente a la violencia y eso debe quedar claramente establecido por el conciliador al entrevistarse con ambas partes. Las partes serán informadas que la intervención de este tercero tiene por finalidad lograr el cese definitivo de la violencia. Si el conciliador durante la entrevista, previa a la audiencia, o durante la audiencia se da cuenta de que no podrá lograr ese objetivo, deberá evitar iniciar la audiencia de conciliación o concluirla, según sea el caso, por cuanto su intervención carecería de sentido.

6.4 El principio de empoderamiento tiene su prueba de máximo rigor en situaciones de violencia, tanto que el conciliador se encargará de velar que la agredida cuente con la capacidad suficiente para participar en la negociaciones que se produzcan. La agredida será escuchada, se estimulará a que brinde sus opiniones, contará con asesores, se le informará sobre sus derechos y otras opciones, y contará con ciertas medidas de seguridad dentro de la audiencia, entre otros. ${ }^{43}$

En el caso peruano existen experiencias interesantes en cuanto a cómo se logra este empoderamiento a través de la mejora de la autoestima. Son justamente las organizaciones de mujeres las que han logrado introducir algunos conceptos -como el de equidad de génerodirigidos a que la mujeres se sientan más seguras de sí mismas y respal-

43 Lamentablemente, el principio de empoderamiento no ha sido reconocido en el artículo $2^{\circ}$ de la Ley de Conciliación No 26872, aunque el reglamento de la Ley No 27007 que concede título de ejecución a las actas de conciliación de las defensorías del niño y del adolescente incorpora este principio: Art. $3^{\circ} \mathrm{D}$. Sup. No 006-99-PROMUDEH. 
dadas por las conciliadoras. ${ }^{44}$ Lamentablemente, el reglamento de la Ley de Conciliación, en su artículo $17^{\circ}$ numeral 1 y 2 , permite que una parte sin necesidad de expresión de causa impida la presencia de los asesores de la contraparte y dispone que, de permanecer los asesores, no tengan derecho a hablar en la audiencia de conciliación.

6.5 El principio de equidad tiene como primer objetivo lograr un acuerdo donde se plasme claramente la forma cómo cesará definitivamente la violencia ${ }^{45}$. Del mismo modo, en tanto que la violencia contra la mujer produce inevitablemente violencia psicológica contra los hijos o familiares cercanos a la víctima, los acuerdos deben de tomar en cuenta las necesidades e intereses de aquellos terceros afectados por la violencia. Adicionalmente, es crucial incluir como parte de los acuerdos una cláusula de garantía para velar por la seguridad de la víctima. ${ }^{46}$

\section{Conclusiones y recomendaciones}

Existe consenso generalizado en pensar que la conciliación no es la solución a la problemática de la violencia familiar. Por otro lado, se reconoce que la conciliación es un medio muy riesgoso para el manejo de situaciones de violencia familiar. Sin embargo, sólo podría ser utilizado cuando de satisfacerse los requisitos necesarios para su puesta en ejecución se determina que existen las mejores probabilidades para lograr el cese definitivo de los actos de violencia -que es en sí una de las finalidades centrales que buscan los mecanismos de erradicación de la violencia-. Aún así, también existen organizaciones de mediación y conciliación que como política han optado entendiblemente por no

44 Ver Conciliación Extrajudicial: Un camino para el logro de la equidad de género y el acceso a la justicia. Tarapoto, PRODEMU: Asociación Promoción y Desarrollo de la Mujer, 1996 e Iván Ormachea. Ch. Diagnóstico del Estado de la Cuestión sobre la Conciliación en Instancias Estatales y Privadas. Op. cit. pp. 49-51.

$45 \mathrm{El}$ artículo $10^{\circ} \mathrm{del}$ reglamento de la Ley de Conciliación reconoce esta dimensión del principio de equidad.

46 Por ejemplo, en casos de violencia leve y focalizada, y bajo condiciones óptimas, se podría acordar que ante un nuevo brote de violencia del agresor, éste se retirará definitivamente del hogar conyugal. 
realizar mediaciones ni conciliaciones en este tipo de casos debido a razones pragmáticas y/o principistas.

A pesar de lo controvertido del tema, me atrevo a sugerir algunos criterios que podrían ayudar a evaluar la pertinencia del uso de la conciliación en estos casos, y que puedan ser de utilidad para aquellas instituciones que han optado por utilizar este mecanismo: la adecuada capacitación de los conciliadores en el tema de violencia familiar e intervención en este tipo de casos, la convicción de la agredida para terminar definitivamente con la violencia, el deseo de separarse definitivamente de la pareja, la existencia de condiciones de seguridad de la agredida y familiares (hijos, etc.), el soporte adecuado de la institución conciliatoria en el caso y el convencimiento de que dentro del caso particular la conciliación se muestra como la mejor alternativa de intervención entre otros posibles.

Aún así, la discusión en torno a la posibilidad de conciliar o no casos de violencia familiar se topa con un conjunto de preguntas sin respuestas y principios encontrados que a la larga no hacen más que desviar la atención en torno a cuestiones mayores que considero fundamentales para mejorar los sistemas integrales de prevención, sanción y erradicación de la violencia familiar. Por lo tanto, creo que la discusión no debe focalizarse solamente en si la conciliación es o no pertinente en [todos] los casos de violencia familiar, si no que el debate debería ampliarse y dividirse en tres niveles:

1. ¿qué mecanismos pueden utilizarse para poner fin a la violencia familiar?

2. ¿en qué momento unos resultan más adecuados/riesgosos que otros? $y$

3. ¿qué requiere urgentemente el sistema de justicia para que su capacidad de prevención y respuesta como verdadero sistema contra la violencia familiar opere eficientemente?

Obviamente que estas preguntas escapan del campo de discusión del presente artículo, sin embargo, es hora de que el trabajo en contra de la violencia familiar se realice a nivel integral e interinstitucional para brindar respuestas a estas interrogantes.

Finalmente, a la luz de la experiencia que tenemos en el campo de la conciliación, la falta de condiciones para realizar una adecuada capa- 
citación en conciliación familiar y las dificultades que plantea el conocimiento del fenómeno de la violencia familiar, se plantean las siguientes sugerencias:

1. La modificación de la Ley No 26260 contra la violencia familiar en la cual se obliga a fiscales y a jueces a convocar imperiosamente a las partes a una audiencia de conciliación como una fase del procedimiento o proceso a seguir respectivamente. Por lo tanto, debe abolirse de nuestra legislación toda norma que establezca canales conciliatorios obligatorios para la solución a la violencia familiar.

2. Del mismo modo, la exclusión de la violencia familiar como materia conciliable obligatoria de la Ley de Conciliación № 26872, como requisito de admisibilidad previa al inicio de un proceso judicial.

3. Modificar el artículo $17^{\circ}$ del reglamento de la Ley de Conciliación, el cual permite que los asesores puedan ser excluidos de la audiencia de conciliación a pedido de cualquiera de las partes y sin expresión de causa alguna, y que prohíbe, la el derecho de expresión del asesor durante el desarrollo de la audiencia de conciliación, por cuanto ambas disposiciones afectan el principio conciliatorio de empoderamiento.

4. Modificar el artículo $15^{\circ}$ de la Ley de Conciliación, puesto que no reconoce la potestad del conciliador de poner fin a la audiencia si las circunstancias no fueran propicias para llevarla a cabo, como en aquellos supuestos de falta de seguridad o temor experimentado por una víctima de violencia familiar.

5. En cuanto a la capacitación de los conciliadores de familia se sugiere que la capacitación incida en una discusión pormenorizada del fenómeno de la violencia familiar, la dinámica familiar y el trabajo detallado en las técnicas necesarias para abordar el fenómeno de la violencia; es decir:

- Capacitar a capacitadores para el dictado de cursos de conciliación familiar a través de instituciones internacionales con experiencia y bajo la organización conjunta del Ministerio de Justicia y el PROMUDEH, en tanto estos organismos están encargados de la capacitación de conciliadores «extrajudiciales» y de los conciliadores de las defensorías del niño y adolescente respectivamente. 
- Incluir como parte de la capacitación de los conciliadores familiares el trabajo pormenorizado para concientizarlos sobre la existencia de diversos mitos sobre la familia, los roles tradicionales de la pareja y la violencia familiar.

- Incluir aspectos de género en la capacitación de los conciliadores familiares.

- Diseñar una política de despistaje de la violencia familiar en toda conciliación en asuntos de familia, para evitar el logro de acuerdos dentro de un marco de temor, intimidación y asimetría de poderes. La Ley de Conciliación ha asumido que los casos de violencia familiar sólo aparecerán cuando la víctima manifiesta esta situación directamente al conciliador, a través de una solicitud de conciliación; sin embargo, la violencia -en no pocas situaciones- es un elemento subyacente a la problemática que impulsa a la agredida a acercarse a un centro de conciliación. Cuando el caso manifieste elementos de violencia familiar, debe ser manejado como tal y exigirse una entrevista por separado a las partes satisfaciendo las cuatro condiciones señaladas líneas arriba, para determinar si el caso es susceptible o no de tramitarse por la vía de la conciliación.

- Establecer un conjunto de pautas y diseñar formatos para la entrevista con la víctima y agresor en los casos donde se compruebe la existencia de violencia familiar, con el fin de evaluar los casos.

- Velar por que las condiciones de seguridad, voluntariedad, competencia y equidad estén presentes antes, durante y después de la audiencia de conciliación.

- Establecer pautas claras para el manejo de la audiencia de conciliación.

- Establecer un sistema de seguridad para el conciliador y el personal de aquellas instancias que intervienen en casos de violencia familiar. Diseñar sistemas de seguridad -al momento de realizar una audiencia de conciliación, por ejemplo- para que durante la ejecución de los acuerdos sobre visitas o alimentos, el agresor no utilice estos encuentros con la agredida para realizar nuevamente acciones de violencia.

6. Establecer un trabajo conjunto e interinstitucional a modo de una infraestructura en contra de la violencia familiar. 
7. Elaborar un Código de Etica del Conciliador en Familia, en la que se señale claramente las pautas a seguir en cuanto a la detección y manejo de situaciones de violencia familiar.

8. Incluir una cláusula en las actas de conciliación en las que se reconozca la culpabilidad del agresor por el acto, con el objeto de que el agresor se haga responsable de sus actos.

9. Incluir dentro de la formación en Derecho la instrucción sobre el fenómeno de la violencia familiar y la forma cómo los abogados pueden asesorar a clientes afectados por la violencia familiar

10. Impulsar políticas para que los conciliadores intervengan como un actor más dentro de un sistema integral de prevención, protección y erradicación de la violencia familiar.

11. Investigar más sobre la realidad de la violencia familiar y sus efectos (sobre la víctima, agresores, hijos, etc.) en el Perú, con el fin de acabar con ciertos mitos y falacias que lamentablemente quedan evidenciadas en las actas de conciliación que vienen suscribiendo diversas instancias estatales y no estatales.

12. Iniciar estudios cualitativos sobre el impacto de la intervención de aquellas instancias que vienen administrando casos de violencia familiar en los que se incluye, entre otras alternativas, a la conciliación, con el fin de evaluar su grado de efectividad en el cese definitivo de la violencia. Nos referimos a las defensorías de los niños y adolescentes, centros de conciliación y otros servicios de asistencia. Lamentablemente, el único estudio cualitativo sobre violencia contra la mujer (Yañez y Dador, 1998) ha demostrado resultados nada satisfactorios a nivel de las instancias estatales.

\section{Bibliografía}

Barsky, Allan E.

1993 «When Advocates and Mediators negotiate» En: Negotiation Journal, Vol. 9 \# 2, April, pp. 115-122.

Bethel, Charles A. y Linda R. Singer.

1982 "Mediation: A new remedy for cases of domestic violence". En: Vermont Law Review. Vol. 7, \# 1 Spring, pp. 15-32. 
Bermúdez Valdivia, Violeta (1998).

1998 «La Violencia familiar y su tratamiento en el derecho peruano" En: Revista de la Academia de la Magistratura. Enero, Nro. 1, Lima: pp. 221-232.

BC Institute on Family Violence.

Family violence in British Columbia: A briefoverview. Ver : http://www.netizen.org/progressive/bcifv/overview/html.

Dutton, Mary Ann y Catherine Waltz L.

1995 "Domestic Violence: understanding how it happens and how to recognize» it En: Family Advocate. American Bar Association. Vol. 17, \# 3. pp. 14-18.

Facio Montejo, Alda, et. al.

1996 Violencia contra la Mujer: reflexiones desde el Derecho. Lima, Manuela Ramos. 213 pp.

Fund for Dispute Resolution.

1993 Report from the Toronto Forum on Woman Abuse and Mediation. Ontario, FDR. 40 pp.

Gerencser, Alison E.

1995 «Family Mediation: Screening for Domestic Abuse» En: Florida State University Law Review. Vol. 23 \#1. pp. 43-54.

Germane, Charlotte; Margaret Johnson y Nancy Lemon.

1985 "Mandatory Custody Mediation and Joint Custody Orders in California: The Danger for Victims of Domestic Violence» En: Berkeley Women's Law Journal. Fll. Vol. 1 \# 1. pp. 175 200.

Knowlton, Douglas D. y Tara Lea Muhlhauser.

1994 "Mediation in the presence of Domestic Violence: is it the light at the end of the tunnel or is a train on the track?n En: North Dakota Law Review. Vol. 70, \# 2. pp. 255-268.

Kruk, Edward. 
"Divorce Mediation and Woman Abuse: Danger and Potential, En: BC Institute on Family Violence, Newsletter. pp. 20-23.

Hart, Barbara J.

1984 Mediation for Battered Women: same song, second verse little bit louder, little bit worse. Ponencia presentada en la Conferencia sobre Mujer y Mediación. New York University School of Law. Jan. 21-22.

Landau, Barbara.

1995 "The Toronto Forum on Women Abuse: the process and the outcome» En: Family and Conciliation Courts Review. Vol. 33, \# 1, January. pp. 65-78.

Ormachea Choque, Iván.

1998

Análisis de la Ley de Conciliación Extrajudicial. Lima, Cultural Cuzco editores. 524 pp.

Diagnóstico del Estado de la Cuestión sobre la Conciliación en Instancias Estatales y Privadas. Lima: junio 1998 (inédito).

PRODEMU: Asociación Promoción y Desarrollo de la Mujer. 1996 Conciliación Extrajudicial: Un camino para el logro de la equidad de género y el acceso a la justicia. Tarapoto, 62 pp.

Salem, Peter y Ann L. Milne.

1995 "Making Mediation Work in a Domestic Violence Case" En: Family Advocate. American Bar Association. Vol. 17, \# 3, pp. 34-38.

Sonkin, D. J.

The Counsellor's Guide to Learning to Live Without Violence. Volcano, California, Volcano Press.

Sun, Myra y Laurie Woods. 
1989 A Mediator's Guide to Domestic Abuse. New York, National Center on Women and Family Law. 91 pp.

United Nations. Commission on Human Rights.

1996 Fifty second session. 4 January. Report of the Special Rapporteur on violence against women, its causes and consequences. Obtenido de la siguiente dirección electrónica: gopher: //gopher.undp.org:70/00/unifem/poli-eco/ poli/whr/vaw/ecn453a1.

Yañez de la Borda, Gina y Jeannie Dador Tozzini.

1998 La Violencia Contra la Mujer: aplicación de la Ley de Violencia Familiar desde una perspectiva de género. Lima, Manuela Ramos. 321 pp. 